\title{
Correction to: Seismic and stress qualification of LMFR fuel rod and simple method for the determination of LBE added mass effect
}

M. Khizer ${ }^{1,2}$ (D) Jian-Wei Chen ${ }^{1}$ (D) Guo-Wei Yang ${ }^{1,2} \cdot$ Qing-Sheng Wu $^{1}$ •

Yong Song ${ }^{1} \cdot$ Yong Zhang ${ }^{1}$

Published online: 1 July 2020

(C) China Science Publishing \& Media Ltd. (Science Press), Shanghai Institute of Applied Physics, the Chinese Academy of Sciences, Chinese Nuclear Society and Springer Nature Singapore Pte Ltd. 2020

\section{Correction to:}

NUCL SCI TECH (2020) 31:5

https://doi.org/10.1007/s41365-019-0721-0

In the original article the authors affiliations are incorrectly published. The authors correct affiliations are provided in this correction article.

The original article can be found online at https:// doi.org/10.1007/s41365-019-0721-0.

$\triangle$ Jian-Wei Chen

jianwei.chen@fds.org.cn

1 Key Laboratory of Neutronics and Radiation Safety, Institute of Nuclear Energy Safety Technology, Chinese Academy of Sciences, Hefei 230031, China

2 University of Science and Technology of China, Hefei 230027, China 